\title{
Effects of Biological Materials and Collection Media on PCR Detection of Tritrichomonas foetus
}

\author{
Kristin A. Clothier ${ }^{1}$, Bret Mc Nabb ${ }^{2}$, Andrea Torain ${ }^{1}$, Steve Reinl ${ }^{1}$, Jeff Ondrak ${ }^{3}$ \\ ${ }^{1}$ California Animal Health and Food Safety Laboratory System, Davis, CA, USA \\ ${ }^{2}$ Department of Population Health and Reproduction, School of Veterinary Medicine, University of California, Davis, Davis, CA, \\ USA \\ ${ }^{3}$ Great Plains Veterinary Educational Center, University of Nebraska-Lincoln, Clay Center, NE, USA \\ Email: *kaclothier@ucdavis.edu
}

How to cite this paper: Clothier, K.A., Nabb, B.M., Torain, A., Reinl, S. and Ondrak, J. (2019) Effects of Biological Materials and Collection Media on PCR Detection of Tritrichomonas foetus. Open Journal of Animal Sciences, 9, 121-128.

https://doi.org/10.4236/ojas.2019.91010

Received: December 13, 2018

Accepted: January 12, 2019

Published: January 15, 2019

Copyright $\odot 2019$ by author(s) and Scientific Research Publishing Inc. This work is licensed under the Creative Commons Attribution International License (CC BY 4.0).

http://creativecommons.org/licenses/by/4.0/

\begin{abstract}
Tritrichomonas foetus is an important pathogen of the bovine reproductive tract causing early embryonic death and abortion in cows and persistent, asymptomatic infection in bulls. PCR detection methods have greatly enhanced diagnostic accuracy over culture; however, pre-analytical sample handling is just as critical as technical performance in detecting this pathogen and is not well studied. The purpose of this study was to investigate the effects of biological materials present in the prepuce on PCR detection of $T$. foetus in a variety of collection media. Simulated preputial samples were created using InPouch $^{\mathrm{TM}}$ (IP) media, lactated ringers solution (LRS), or sterile saline (SAL); inoculated with low numbers of one of three T. foetus strains; and spiked with either blood, semen, urine, or sham treatment. Samples were transported to the lab, placed in growth media (LRS and SAL samples), incubated, and tested for $T$. foetus by PCR. Samples containing urine had statistically significantly greater mean $\mathrm{Ct}$ values $(P=0.008)$ than samples containing other materials, seen most dramatically in IP $(P<0.0001$. $)$ Urine contamination resulted in significantly $(P=0.037)$ fewer samples being identified as "positive" for $T$. foetus. Overall, SAL collections also had significantly higher mean Ct than IP or LRS $(P<0.001)$, and were less likely $(P=0.018)$ to results in classification as a "positive" sample. Results of this study indicate that collection media and biological materials can affect $T$. foetus PCR detection. The presence of urine in preputial samples can result in false negative results, while blood had no detrimental effects.
\end{abstract}

\section{Keywords}

Tritrichomonas foetus, PCR Detection, Urine, Semen, Blood 


\section{Introduction}

Tritrichomonas foetus is an important pathogen of the bovine reproductive tract causing early embryonic death and abortion [1] [2]. This protozoal organism colonizes the epithelium of the penis and prepuce in the bull and has been identified in the distal urethra; however, not in the penile or prostatic urethra, accessory sex glands, nor epididymis [1] [3]. Attachment to urogenital epithelium is thought to occur via glycoprotein adhesins which results in minimal immune recognition or site-specific inflammation; consequently, clearance of the organism is rare, particularly in older bulls [1] [3] [4] [5].

Transmission of $T$. foetus to cows primarily occurs during breeding and is highly efficient, with up to $95 \%$ of females becoming infected after a single mating [6] [7] [8]. Economic impacts of T. foetus on a herd include loss of income from fewer and lighter-weight calves to market at weaning, loss of genetic potential from culled animals, costs of replacing infected bulls, laboratory fees for diagnostic testing, and feed costs for non-productive animals [1] [7] [9]. No approved treatments exist to clear the infection; consequently, identification and removal of infected bulls is the best way to minimize T. foetus impacts [8] [9].

Molecular diagnostic methods with high sensitivity and specificity have greatly improved the analytical detection of $T$. foetus [10] [11]. Pre-analytical sample handling, however, can account for up to $62 \%$ of diagnostic errors and it is critical to address sample collection and transport when evaluating diagnostic accuracy [9] [12]. The purpose of the present study was to evaluate the presence of biological materials that are commonly present in bull preputial samples on the PCR detection accuracy of $T$. foetus utilizing three different collection media.

\section{Materials and Methods}

\subsection{Sample Preparation}

The collection media used in this study included InPouch ${ }^{\mathrm{TM}}$ (IP) media (individual pouch), $1.5 \mathrm{~mL}$ of LRS, or $1.5 \mathrm{~mL}$ sterile saline (SAL); the three T. foetus strains used were the laboratory quality control strain, a clinical isolate from 1986 and confirmed by phenotypic and genotypic methods [PCR \& RFLP] as $T$. foetus (QC) and two field strains. (FS1 recovered from smegma cultures submitted to the U.C. Davis Veterinary Medical Teaching Hospital and FS2 recovered from smegma cultures submitted to the California Animal Health and Food Safety Laboratory System.) Three replicates for each treatment group were created in the field and transported to the lab to mimic natural collection conditions.

Each sample was inoculated with approximately 150 organisms of an individual strain to simulate low levels of $T$. foetus colonization followed by one type of biological material $(0.1 \mathrm{~mL}$ freshly-collected whole blood [BLOOD], $0.5 \mathrm{~mL}$ of freshly collected urine [URINE], $0.1 \mathrm{~mL}$ of freshly-collected semen [SEMEN], or $0.1 \mathrm{~mL}$ sterile saline [SHAM].) Volumes of biological materials were chosen to simulate the quantities that are consistent with what has been obtained during a collection of a preputial scraping or wash, particularly at the time of a breeding 
soundness exam. The bull used for collection of biological samples had a complete blood count $(\mathrm{CBC})$ and urinalysis that were within normal limits and was tested negative for $T$. foetus by PCR at the time of biological material collection.

Samples were transported to the lab within three hours of creation. The IP samples were incubated at $35^{\circ} \mathrm{C}$ for 24 hours; mixed well; and $1 \mathrm{~mL}$ aliquots were collected for testing. SAL and LRS samples were held at room temperature for one hour and were then inoculated into $10 \mathrm{~mL}$ tubes of modified Diamonds Plastridge media (DPM) [13] which contained $1.0 \%$ peptone-based broth, $1.0 \%$ dextrose, $0.1 \%$ sodium chloride, $0.3 \%$ beef extract, 5000 units of penicillin $/ \mathrm{mL}$, $0.1 \%$ of streptomycin, $0.3 \%$ ovine serum, and $0.07 \%$ agar. Inoculated DPM tubes were incubated at $35^{\circ} \mathrm{C}$ for 48 hours, after which $1-\mathrm{mL}$ aliquots were collected from the base of the tube for PCR testing. Due to the time $T$. foetus spent in non-growth media (SAL or LRS) before inoculation, DPM media is incubated for 48 hours per laboratory protocol to better support organism recovery.

\subsection{Real-Time PCR Assay}

Testing on IP was conducted as previously described [11]. Briefly, a $1 \mathrm{~mL}$ volume of media was centrifuged at $3500 \mathrm{rpm}$ at room temperature for $3 \mathrm{~min}$, decanted, and re-suspended in $300 \mu \mathrm{L}$ of $1 \times$ PBS. Due to the presence of agar in DPM that can interfere with PCR reactions [14], testing performance in this medium was optimized using centrifugation of the $1 \mathrm{~mL}$ aliquot at $3500 \mathrm{rpm}$ at room temperature for $3 \mathrm{~min}$ followed by decanting of supernatant, and re-suspension of the pellet in $200 \mu \mathrm{L}$ of $1 \times$ PBS.

DNA extraction was performed using MagMAX 96 Viral RNA Isolation Kit for total nucleic acid from low-cellularity biological samples (Life Technologies, Grand Island, NY) modified for T. foetus extraction with a final volume of 85 $\mu \mathrm{L}$. Real time PCR was performed in a $33 \mu \mathrm{L}$ reaction mixture containing $8 \mu \mathrm{L}$ of template DNA; $1 \mu \mathrm{L}$ of VetMAX T. foetus primer-probe reagent (Life Technologies, Grand Island, NY); $12.5 \mu \mathrm{L}$ of VetMAX Plus qPCR Master Mix, (Life Technologies, Grand Island, NY); $3.5 \mu \mathrm{L}$ of sterile water, and $8 \mu \mathrm{L}$ of internal amplification control (IAC) DNA (Life Technologies, Grand Island, NY). PCR was conducted on the ABI 7500 Fast (Sunnyvale, CA); reactions included initial polymerase activation at $95^{\circ} \mathrm{C}$ for $10 \mathrm{~min}$, followed by 40 cycles of DNA dissociation at $97^{\circ} \mathrm{C}$ for $5 \mathrm{~s}$ and annealing/extension at $55^{\circ} \mathrm{C}$ for $40 \mathrm{~s}$. Results were expressed as cycles to threshold $(\mathrm{Ct})$ values, and simulated samples were PCR-tested in triplicate to obtain mean Ct values for each. Non- $T$. foetus, internal amplification control (IAC) DNA was included with all reactions to ensure that the PCR reactions performed as expected and no PCR inhibition was present in tested samples. Positive and negative extraction and amplification controls were tested with each run to ensure consistent performance of the assay.

\subsection{Data Analysis}

Statistical analyses were performed using SAS Version 9.4 (SAS Institute, Inc., Cary, NC, USA.) Mean Ct values were assessed using a least squares means pro- 
cedure between $T$. foetus strain, collection media, and biological treatments. A $\mathrm{Ct}$ value of 40.0 was used for calculation of summary statistics of samples with no DNA detected. Comparisons of percent positive samples between treatment and media using the laboratory cut-off of 37.0 were performed using Fisher's exact test.

\section{Results}

\subsection{Evaluation of Biological Materials and Collection Media on T. foetus Detection by PCR}

The effects of the biological material on $T$. foetus PCR detection are shown in Figure 1. Across all media and $T$. foetus strains, samples containing urine had statistically significantly higher mean Ct values $(36.6, P=0.008)$ than all other treatments (34.6 - 34.9). The effects were most evident in samples inoculated into IP media, in which mean $\mathrm{Ct}$ values in urine-containing samples were five cycles greater (mean $\mathrm{Ct}=38.5$ ) than samples containing blood, semen, or no biological treatment (mean Ct 33.1 - 33.9, $P<0.0001$.) Urine (mean $\mathrm{Ct}=37.2$ ) also significantly inhibited detection $(P=0.002)$ of $T$. foetus in SAL samples $(P=$ 0.002 ) compared with other biological materials (mean $\mathrm{Ct}=34.8$.)

Figure 2 shows that across all treatments, samples collected in IP and LRS (mean $\mathrm{Ct}=34.7)$ had mean $\mathrm{Ct}$ values which were significantly lower than samples collected into SAL (mean $\mathrm{Ct}=36.3, P<0.001$.) Biological materials had no effect on samples collected into LRS. Samples inoculated into IP (mean Ct $=33.1$ ) had significantly lower Ct values than LRS- (mean $\mathrm{Ct}=35.3$ ) or SAL-inoculated samples (mean $\mathrm{Ct}=36.4)$ when spiked with semen $(P<0.001)$ but not samples spiked with blood (mean Ct 33.9 - 35.1, $P=0.22$.) SAL had significantly higher mean $\mathrm{Ct}$ values for samples containing semen (mean $\mathrm{Ct}=36.4$ ) or urine mean $\mathrm{Ct}=37.4)$ than for samples containing blood (mean $\mathrm{Ct}=35.1, P=0.046$.)

\subsection{Assessment of Biological Material and Collection Media on T. foetus Classification}

Percentage of positive samples detected using the laboratory cut-off is shown in

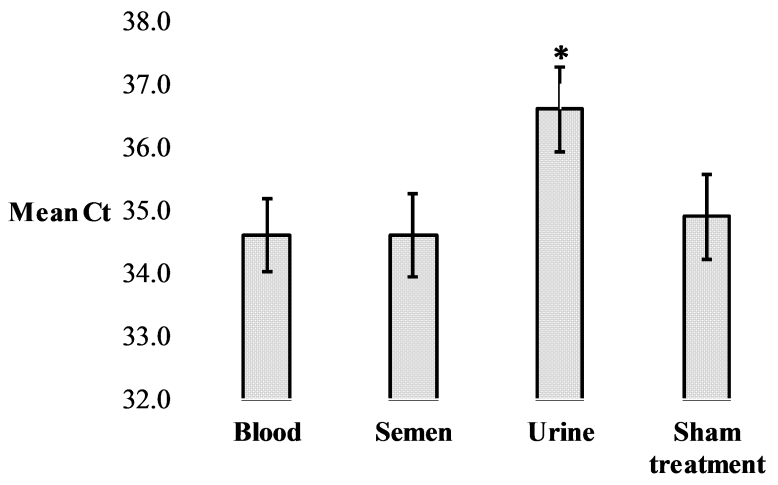

Figure 1. Mean Ct values for T. foetus DNA in simulated preputial samples spiked with blood, semen, urine, or sham treatment. ${ }^{*}$ Mean Ct was significantly greater than other treatments $(P=0.008)$. 


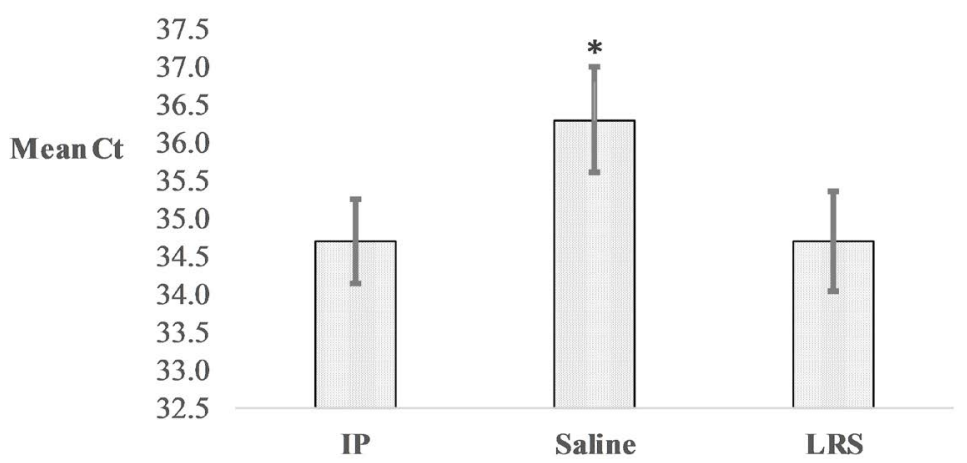

Figure 2. Mean Ct values for T. foetus DNA in simulated preputial samples collected in InPouch ${ }^{\mathrm{TM}}$ media (IP), sterile saline (SAL), or lactated Ringer's solution (LRS.) ${ }^{\star} \mathrm{Mean} \mathrm{Ct}$ was significantly greater than for other media $(P<0.001)$.

Figure 3(a) for biological media and Figure 3(b) for collection media. Overall, samples containing urine were significantly less likely $(P=0.037)$ to be classified as "positive" than any of the other treatments. Nearly $19 \%$ of $T$. foetus-spiked samples containing urine had no DNA detected at all during PCR testing, with $33 \%$ of FS1 and $55.5 \%$ of FS2 samples with urine yielding false-negative results. Regardless of the type of biological material, samples which were inoculated into SAL also had significantly fewer classified positive results $(P=0.018)$ with $26.0 \%$ having no DNA detected.

\section{Discussion}

Identification of bulls, which are colonized with T. foetus, continues to be a costly and frustrating problem to the cattle industry [1] [3]. As a fastidious organism which is susceptible to DNA degradation in the face of imperfect environmental conditions, T. foetus detection is critical to any control program [15] [16]. The implementation of diagnostic methods with high sensitivity and specificity such as real-time PCR can dramatically improve identification of infected bulls, particularly those that are colonized with low numbers of organisms expected during natural infection [15] [17]. In the present study, samples were created with a low number of $T$. foetus (50 - 60 organisms $/ \mathrm{ml}$ in IP system) to assess how sample conditions affect DNA detection in these challenging samples.

This study demonstrates the importance of mimicking true sample conditions, including the use of field isolates, when evaluating diagnostic procedures for accuracy. The presence of urine interfered with DNA detection, resulting in higher mean $\mathrm{Ct}$ values for all three $T$. foetus strains evaluated in this study; however, the effects were seen most dramatically in field strains, with one-third (FS1) to one-half (FS2) of samples producing false negative results. T. foetus has been shown to be susceptible to extremes in $\mathrm{pH}$, with optimal survival and DNA detection at $6.8-7.0$, and can tolerate ranges of $6.0-8.5$ [16] [18]. The urinalysis on this bull showed his urine $\mathrm{pH}$ to be 9.0, which may account for the greater $\mathrm{Ct}$ values and lower detection in SAL samples compared to IP and LRS which are designed to maintain a neutral $\mathrm{pH}$. Additionally, our laboratory classifies bulls 

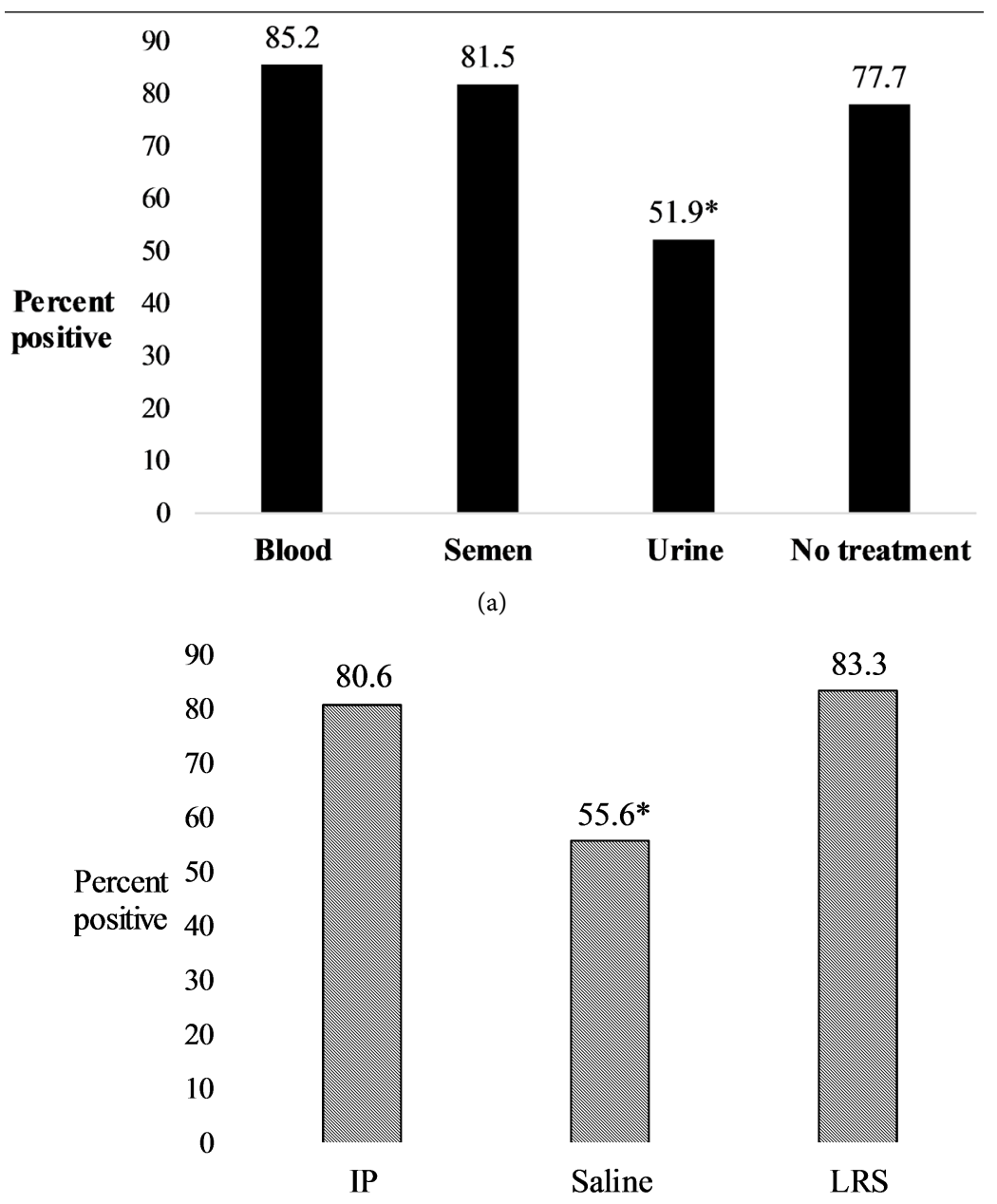

(b)

Figure 3. Percent positive for T. foetus DNA in simulated preputial samples (a) spiked with blood, semen, urine, or sham treatment $\left({ }^{*}\right.$ percent positive was significantly lower than other treatments $[P=0.037])$ and $(b)$ collected in InPouch $^{\mathrm{TM}}$ media (IP), sterile saline (SAL), or lactated Ringer’s solution (LRS) ( ${ }^{\star}$ percent positive was significantly lower than other media $[P=0.018]$.

with high Ct values (37 - 39) as "inconclusive" since these values are near the limit of detection for the assay. PCR testing in this study identified two samples each spiked with blood or semen but seven samples spiked with urine fell into in this category.

Overall, samples created in SAL had significantly greater mean Ct values for T. foetus, even though samples were inoculated into DPM culture media within four hours of collection. Isotonic saline appears to do a poor job of maintaining conditions that preserve $T$. foetus for detection. LRS provides superior buffering capacities under physiologic conditions and was shown to maintain $\mathrm{pH}$ significantly better than isotonic saline even within the first 2 hours of administration [19].

There were several limitations to the present study. The $T$. foetus spiking concentration was selected to mimic bulls colonized with low numbers of organ- 
isms but does not provide data on how these conditions would affect detection of larger numbers of organisms. Biological materials were collected from a single bull and volumes were chosen to simulate what might be obtained during preputial scraping; the effects of different animals and different volumes of these materials were not evaluated and may impact the extent of their presence on $T$. foetus detection. Testing was performed on incubated media to enhance the survival of $T$. foetus and preservation of DNA for detection; however, LRS and SAL samples inoculated into DPM were incubated for 48 hours compared with IP incubated for 24 hours per laboratory protocol which would be expected to produce lower $\mathrm{Ct}$ values and affect comparison between collection media.

The present study demonstrates that to maximize T. foetus detection, particularly from bulls harboring low numbers of organisms, collection procedures should include use of a media which provides an environment simulating physiologic conditions and avoiding urine collection at the time of preputial sampling. Even though $T$. foetus strains collected into SAL had only four hours of contact before DPM inoculation, DNA detection was significantly impaired over IP and LRS collections, which may indicate that a more complex and balanced support media is needed to support $T$. foetus prior to arrival at a diagnostic facility.

\section{Conflicts of Interest}

The authors declared no potential conflict of interest with respect to the research, authorship and/or publication of this article.

\section{References}

[1] Ondrak, J.D. (2016) Tritrichomonas foetus Prevention and Control in Cattle. Veterinary Clinics of North America: Food Animal Practice, 32, 411-423. https://doi.org/10.1016/j.cvfa.2016.01.010

[2] Ondrak, J.D., Keen, J.E., Rupp, G.P., Kennedy, J.A., McVey, D.S. and Baker, W.D. (2010) Repeated Testing by Use of Culture and PCR Assay to Detect Tritrichomonas foetus Carrier Bulls in an Infected Nebraska Herd. Journal of the American Veterinary Medical Association, 237, 1068-1073. https://doi.org/10.2460/javma.237.9.1068

[3] Michi, A.N., Favetto, P.H., Kastelic, J. and Cobo, E.R. (2016) A Review of Sexually Transmitted Bovine Trichomoniasis and Campylobacteriosis Affecting Cattle Reproductive Health. Theriogenology, 85, 781-791. https://doi.org/10.1016/j.theriogenology.2015.10.037

[4] Cobo, E.R., Corbeil, L.B. and BonDurant, R.H. (2011) Immunity to Infections in the Lower Genital Tract of Bulls. Journal of Reproductive Immunology, 89, 55-61. https://doi.org/10.1016/j.jri.2011.02.002

[5] Greenwell, P., Younes, M. and Rughooputh, S. (2008) Purification and Analysis of DNases of Tritrichomonas foetus. Evidence That These Enzymes Are Glycoproteins. International Journal for Parasitology, 38, 749-756. https://doi.org/10.1016/j.ijpara.2007.10.012

[6] Dewell, G.A., Phillips, P.E., Dohlman, T.M., Harmon, K.M. and Gauger, P.C. (2016) Validation of a Gauze Sponge Sampling Methodology to Detect Tritrichomonas 
foetus by Real-Time PCR. Journal of Veterinary Diagnostic Investigation, 28, 595-598. https://doi.org/10.1177/1040638716653637

[7] Rae, D.O. and Crews, J.E. (2006) Tritrichomonas foetus. Veterinary Clinics of North America: Food Animal Practice, 22, 595-611. https://doi.org/10.1016/j.cvfa.2006.07.001

[8] Yao, C. (2013) Diagnosis of Tritrichomonas foetus-Infected Bulls, an Ultimate Approach to Eradicate Bovine Trichomoniasis in US Cattle? Journal of Medical Microbiology, 62, 1-9. https://doi.org/10.1099/jmm.0.047365-0

[9] Okafor, C.C., Strickland, L.G., Jones, B.M., Kania, S., Anderson, D.E. and Whitlock, B.K. (2017) Prevalence of Tritrichomonas foetus in Tennessee Bulls. Veterinary Parasitology, 243, 169-175. https://doi.org/10.1016/j.vetpar.2017.06.024

[10] GinterSummarell, C.C., Hairgrove, T.B., Schroeder, M.E., Conley, R. and Bounpheng, M.A. (2018) Improvements in Tritrichomonas foetus Molecular Testing. Journal of Veterinary Diagnostic Investigation, 30, 603-608. https://doi.org/10.1177/1040638718767943

[11] McMillen, L. and Lew, A.E. (2006) Improved Detection of Tritrichomonas foetus in Bovine Diagnostic Specimens Using a Novel Probe-Based Real Time PCR Assay. Veterinary Parasitology, 141, 204-215. https://doi.org/10.1016/j.vetpar.2006.06.012

[12] Plebani, M. (2010) The Detection and Prevention of Errors in Laboratory Medicine. Annals of Clinical Biochemistry, 47, 101-110. https://doi.org/10.1258/acb.2009.009222

[13] Diamond, L.S. (1957) The Establishment of Various Trichomonads of Animals and Man in Axenic Cultures. Journal of Parasitology, 43, 488-490. https://doi.org/10.2307/3274682

[14] Gibb, A.P. and Wong, S. (1998) Inhibition of PCR by Agar from Bacteriological Transport Media. Journal of Clinical Microbiology, 36, 275-276.

https://www.ncbi.nlm.nih.gov/pubmed/9431965

[15] Clavijo, A., Erol, E., Sneed, L., Sun, F. and Swinford, A. (2011) The Influence of Temperature and Simulated Transport Conditions of Diagnostic Samples on Real-Time Polymerase Chain Reaction for the Detection of Tritrichomonas foetus DNA. Journal of Veterinary Diagnostic Investigation, 23, 982-985. https://doi.org/10.1177/1040638711417143

[16] Clothier, K.A., Villanueva, M., Torain, A., Hult, C. and Wallace, R. (2015) Effects of Bacterial Contamination of Media on the Diagnosis of Tritrichomonas foetus by Culture and Real-Time PCR. Veterinary Parasitology, 208, 143-149. https://doi.org/10.1016/j.vetpar.2015.01.006

[17] OIE (World Organization for Animal Health) (2018) Chapter 2.4.16 Trichomonosis. OIE Terrestrial Manual, 1-12.

[18] Lyford, H.S. (1941) Some Reactions of a Pathogenic Flagellate, Trichomonas foetus, to Environmental Changes in Bacteria-Free Culture. American Journal of Epidemiology, 33, 69-87. https://doi.org/10.1093/oxfordjournals.aje.a118712

[19] Marino, P.L. (2003) The ICU Book. 3rd Edition, Lippencott, Williams, \& Wilkins, Philadelphia. 